\title{
Judicialização e subpolítica médica
}

\section{| ${ }^{1}$ Thiago Marques Leão, ${ }^{2}$ Aurea Maria Zöllner lanni |}

Resumo: O objetivo deste artigo é discutir o fenômeno da judicialização e a subpolítica médica na contemporaneidade. A judicialização é identificada como o envolvimento do Poder Judiciário na esfera política na tutela de interesses individuais, como uma interferência no planejamento das políticas públicas. As decisôes judiciais acabariam definindo políticas, à margem do modelo democrático da modernidade industrial. Diversas pesquisas defendem que o Judiciário tende a atender estas demandas, evocadas sob o fundamento da garantia da saúde e vida, abalizadas pelas normas de direito constitucional à saúde e profissionais médicos. Mas a judicialização pode ser também caracterizada como eco de um processo reflexivo da modernidade, no qual direitos fundamentais estabelecidos potencializam uma nova cultura política. Os cidadãos utilizam meios não tradicionais de intervenção e controle público e judicial, buscando defender seus interesses e direitos. O próprio fundamento fático das demandas é construído reflexivamente pelo saber médico, impermeável a formas tradicionais de controle externo. Isto gera uma judicialização pautada pela medicina e favorece a expansão do campo de atuação médica, e do mercado e pesquisa para a indústria médico-hospitalar e farmacêutica. Tanto sociedade como Estado acabam sendo obrigados a recorrer a normas e conhecimentos medicinalmente constituídos e monopolizados, em uma estratégia reflexiva de mercado.

> Palavras-chave: judicialização; medicalização; individualização subpolítica médica; sociedade de risco; Saúde Pública.

\footnotetext{
${ }^{1}$ Faculdade de Saúde Pública, Universidade de São Paulo. São Paulo-SP, Brasil (thmleao@ gmail.com).

ORCID: 0000-0003-2402-9898

2 Faculdade de Saúde Pública, Universidade de São Paulo. São Paulo-SP, Brasil (aureanni@usp.br). ORCID: 0000-0003-1366-8651
} 


\section{Introdução}

Este artigo discute o fenômeno da "judicialização da saúde" em relação às estratégias (sub)políticas da medicina, na perspectiva de uma "crítica à crítica" da crescente busca pela tutela jurisdicional, que leva à intervenção do Poder Judiciário nas políticas públicas de saúde no Brasil. Quer-se, com isto, propor novas possibilidades analíticas, em direção a um novo olhar que reconheça a complexidade do fenômeno e seus desdobramentos, para melhor compreendê-lo.

A crítica usual, pautada pela tripartição clássica dos Poderes e centrada na atuação do Judiciário, do lugar da política e do exercício da cidadania, parece ser insuficiente diante da crescente busca pela concretização do direito social à saúde, pela judicialização das políticas públicas. Acreditamos que isso decorra da impermeabilidade dessa crítica às mudanças do cenário social e político contemporâneo. Por isso, propomos contextualizar e repensar a judicialização na sociedade contemporânea, orientados, centralmente, pelas reflexôes de Ulrich Beck e sua teoria da modernização reflexiva.

\section{A sociedade de risco}

Ao nos referirmos à sociedade contemporânea, compreendemos "como aquela também denominada de pós-moderna, tardo-moderna, industrial tardia etc., [que] configura-se a partir de meados da segunda metade do século XX”, produto de profundas mudanças nas sociedades industriais ocidentais (IANNI, 2011, p. 33) num contexto de modernização reflexiva.

Modernização reflexiva porque a sociedade industrial clássica passa por autotransformaçóes em suas estruturas fundantes, condições de produção de riqueza e desigualdade (BECK, 2010; 2012). Esta corrosão autodestrutiva atinge o próprio cerne da modernidade industrial, seu entendimento e produção técnico-científicos, a família nuclear, o universo do trabalho e os papéis estamentais do masculino e feminino. Um fenômeno que decorre não da crise da modernidade, mas é fruto do seu próprio desenvolvimento bem-sucedido e radicalizado. Diferentemente do primeiro processo de modernização, ocorrido nos séculos XVIII e XIX, em que se pôs em xeque as certezas religiosas da sociedade feudal, são agora postas em xeque as certezas da própria sociedade industrial, lançando o indivíduo nas águas turbulentas da Contemporaneidade. 
A autotransformação promovida por este processo de segunda modernização da sociedade industrial clássica leva à emergência do que Beck denomina de Sociedade de Risco: "Este conceito designa uma fase no desenvolvimento da sociedade moderna, em que os riscos sociais, políticos, econômicos e individuais tendem cada vez mais a escapar das instituiçôes para o controle e a proteçâo da sociedade industrial" (BECK, 2012, p. 17). Neste contexto, os riscos são resultado das decisóes humanas e consequências, ou efeitos colaterais, imprevisíveis e incontroláveis do sucesso e radicalização dos processos modernos (BECK, 2008). Os riscos não são percebidos como exteriores, naturais ou divinos, mas são antes uma produção social, cultural e histórica decorrente da radicalização da sociedade industrial, resultado das escolhas tomadas pelos indivíduos, seja na esfera de suas decisóes pessoais, ou na chamada esfera pública - distinção cada vez menos relevante na contemporaneidade.

A Sociedade de Risco produz o que Beck denomina de processo individualizatório, ou individualização, que corresponde, em primeiro lugar, à desconstrução da estrutura da vida constitutiva das sociedades industriais modernas, e à (re)construção de uma nova estrutura, na qual os indivíduos devem produzir, decidir e se responsabilizar por suas próprias biografias, por suas próprias trajetórias autobiográficas. Aqui, os projetos de vida, os riscos, as decisóes e as escolhas e suas consequências passam a ser percebidas a partir do indivíduo, centradas no indivíduo. A individualização conduz o sujeito à esteira de produção biográfico-institucional: da educação formal, ao emprego e à inserção no mercado de trabalho, aprendizado de habilidades profissionais, modelos de comportamento socialmente aceitos, estilos de vida saudável, produtividade e consumo.

No contexto biográfico-institucional, as escolhas são compreendidas como imperativos individuais e, quando malfeitas, repercutem como responsabilidade individual. Ainda que as consequências reflitam, de fato, questóes coletivas produzidas socialmente, é a escolha individual que parece lançar o indivíduo à sua própria sorte, com todos os riscos que isto implica. Nesse sentido, o processo de individualização torna-se, inevitavelmente, político e produz uma contradição intrínseca, uma subjetividade centrada no individuo que, por sua vez, reproduz os elementos concretos e as relaçóes intersubjetivas da sociedade individualizada. Esta centralidade do indivíduo nas sociedades contemporâneas produz um novo cenário, no qual as instituições tornam-se progressivamente dependentes dos indivíduos e 
das iniciativas de grupos de cidadãos (BECK, 2012) - um fenômeno que decorre do próprio aprofundamento jurídico-político da democracia social moderna.

No quadro do processo de individualização, saúde e responsabilidade individual se tornam eixos axiológicos da experiência subjetiva em sociedade: a saúde é uma exigência para o desempenho no mercado de trabalho, nas relaçóes sexual-afetivas, para aproveitar as experiências e permitir a realização pessoal dos projetos de vida, e assim por diante. Com o avanço da Sociedade de Risco, cada vez mais o indivíduo é instado a fazer avaliaçóes e planejar sua vida a longo prazo, considerando e assumindo riscos (as ameaças e possibilidades que se abrem). Nestas circunstâncias, o cuidado constante com a saúde se torna uma espécie de valor fundamental, ao lado da responsabilidade individual (BECK, 1995; BECK-GERNSHEIM 1995; BECK; BECK-GERNSHEIM, 2002), exigido em uma sociedade altamente diferenciada, e em um mercado altamente competitivo. Adoecer é um perigo que nos ameaça, potencialmente, a todos, em um contexto de riscos coletivamente individualizados.

Sob o signo da responsabilidade individual, a saúde deve ser garantida por todos os meios possíveis, em formas individuais de ação política com "cidadãos [que] sabem dispor de todos os meios de intervenção e controle público e judicial para a defesa de seus interesses e direitos", levando a uma dissolução das fronteiras tradicionais da política (BECK, 2010, p. 278). A percepção sobre os espaços e atores políticos tradicionais (Parlamento, partidos, sindicatos etc.) é crescentemente marcada pela desconfiança e descrédito, percebidos como incompetentes, privilegiados, corruptos e distantes das verdadeiras preocupaçóes dos indivíduos (LIPOVETSKY, 2007). Neste sentido, não se crê mais na resolução de conflitos e demandas a partir de debates legislativos, desconfia-se de políticas públicas do Executivo, e as instituiçôes sociais típicas da Modernidade industrial se mostram incapazes de lidar com os riscos e crises sociopolíticas que elas mesmas produzem.

Portanto, ao indivíduo resta a responsabilidade pela garantia de seus direitos, migrando da institucionalidade coletiva do sistema político para a lógica individual do sistema jurídico e das açôes judiciais, com sua legitimação técnica, (tradicionalmente) não política e alheia à participação democrática. Isto se dá em um cenário de dissolução das seguranças ocupacionais, de aceleração do ritmo de vida, sobrecarga individual, alta competitividade e exigências de desempenho profissional: é a radicalização do projeto moderno ocidental que contextualiza esta espécie de individualização da ação política no Brasil em relação aos direitos sociais 
e, notadamente, o direito à saúde - valor axial da contemporaneidade. O Estado de bem-estar e o relativo sucesso dos projetos democráticos modernos deslocam o centro da arena político-decisória. Os ganhos em direitos e cidadania dissolvem a separação tradicional entre esfera pública e privada, entre citoyen e bourgeois, como figuras do indivíduo que, anteriormente divido em dois, exercia sua autonomia pública nos espaços de participação política tradicionais e sua autonomia privada (e não política) na esfera dos interesses particulares da família nuclear e técnicofinanceiros, respectivamente (BECK, 2010).

No caso da judicialização, por exemplo, que se traduz na busca por tutela jurisdicional dos direitos sociais, por meio da intervençáo do Poder Judiciário sobre atribuiçóes típicas do Poder Executivo e/ou Legislativo, há de um lado o reconhecimento pelo cidadáo de sua titularidade como sujeito de direitos e da responsabilidade do Estado; de outro, um processo de consolidação de instituiçôes como o Ministério Público e a Defensoria Pública, que, ainda que não capitaneiem a judicialização, só puderam assumir o papel que desempenham hoje em decorrência do alargamento do Estado de bem-estar e do desdobramento do processo de redemocratização iniciado nas décadas de 1980 e 1990 no Brasil.

As fronteiras entre o privado e público, entre o político e o não político, no processo de individualização e modernização, perdem consistência progressivamente. O alargamento da democracia e do controle social, bem como a ampliação da atuaçâo dos atores políticos tradicionais, perde seu distanciamento e seu caráter impositivo e está cada vez mais submetido à crítica, à intervenção e à discussão, pelos meios disponíveis e que mais se mostrem eficazes (BECK, 2010). Nesse sentido, o Poder Judiciário apresenta-se como canal acessível a uma parcela da população que o identifica como instituição capaz de efetivar o direito individual à saúde e demanda a tutela jurisdicional sobre os seus interesses.

[...] sempre que direitos são garantidos, que ônus sociais são redistribuídos, que a participação é viabilizada, que cidadáos se tornam ativos, a política avança um pouco mais na dissolução de suas fronteiras e em sua generalização. (BECK, 2010, p. 287)

Seja qual for o mecanismo de pressão social, a política é cada vez mais desconcentrada em relação ao Estado e às instâncias políticas tradicionais da sociedade industrial. Com o aprofundamento democrático, estabelecem-se redes de pressão, controle, negociação e participação que deslocam o centro do palco e o protagonismo do teatro público. Nas palavras de Beck (2010, p. 286), “O sistema político-administrativo já 
não pode então continuar a ser o lugar único ou central dos acontecimentos políticos”. Com a ampliação dos direitos sociais e políticos, e a dissolução de vínculos e formas tradicionais da política moderno-industrial, recai sobre o indivíduo o ônus de buscar, por todos os meios possíveis, a garantia de direitos.

\section{A crítica à judicialização no Brasil}

A Constituição Federal de 1988 (CF/88) é marco formal de retomada do processo democrático e do projeto de Estado social brasileiro, depois de mais de 20 anos sob regime militar, instaurado pelo golpe de 1964. A CF/1988 elenca um rol de direitos fundamentais individuais e sociais que refletem, no ordenamento jurídico interno, a perspectiva moderna dos direitos humanos e o projeto de Estado social reivindicado pelos movimentos que se mobilizaram pela redemocratização do Brasil. Neste contexto, abriu-se espaço para um ambiente de reconhecimento e emergência dos direitos humanos e, ao menos, potencializou a garantia do direito à saúde.

O processo de restabelecimento do Estado democrático de direito no Brasil, orientado por princípios democráticos, possibilitou a institucionalização das demandas populares por direitos políticos e sociais. Portanto, uma das principais conquistas incorporadas à CF/88 foi a constitucionalização do direito fundamental à saúde e a proposição do Sistema Único de Saúde - SUS, universal, integral e gratuito. Uma inovação importante, tendo em vista que até então, em termos constitucionais, a saúde gozava de uma proteção jurídica indireta e limitada a normas sobre vigilância sanitária e controle de drogas e medicamentos (SARLET; FIGUEIREDO, 2009; SOLON, 2009).

$\mathrm{Na}$ esteira destas conquistas e inovaçóes constitucionais, a judicialização e crescente litigiosidade em saúde cresce e, continuamente, ganha relevância tanto acadêmica quanto prática. Há uma busca crescente pela tutela jurisdicional do direito à saúde, enquanto gestores, juristas e outros atores sociais são confrontados com o fenômeno. Segundos dados da Advocacia-Geral da Uniấo - AGU (AGU, 2013), houve um aumento de aproximadamente $22 \%$ no número de açóes judiciais no curto período de dois anos (2009-2011), apenas contando aquelas em face da União. Em gastos globais, o montante cresceu de aproximadamente R \$ 9,17 milhóes, em 2006, para mais de R \$ 1,1 bilhão em 2015 (AGU, 2017). Reproduzimos o gráfico apresentado pela AGU: 
Gráfico 1. Gasto público global 2006-2015

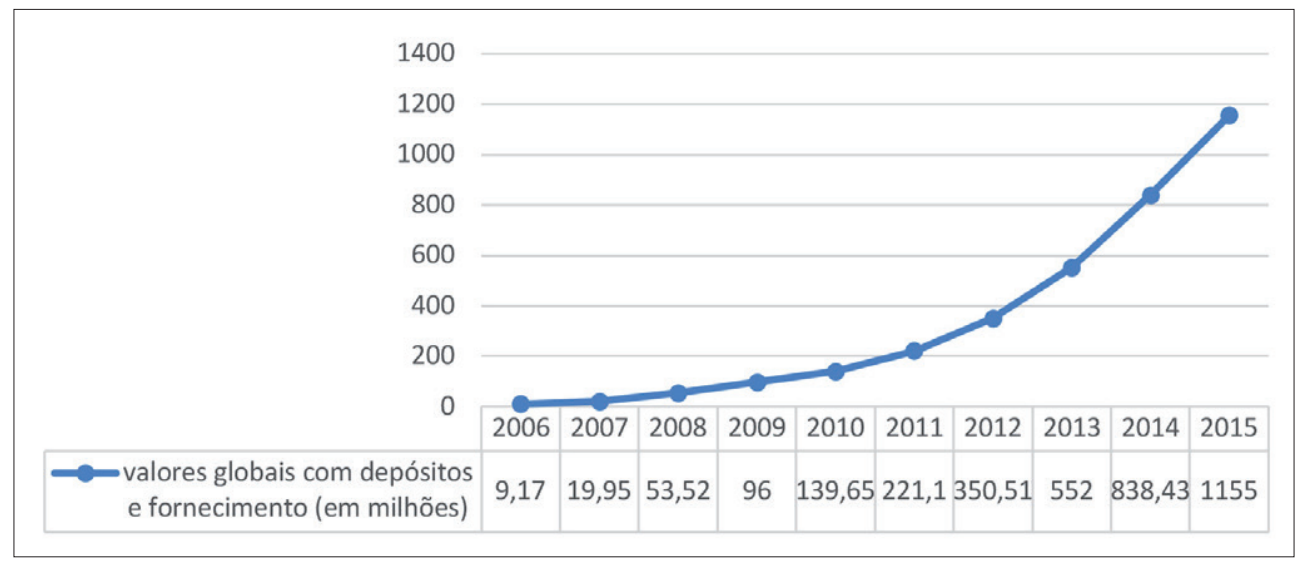

Fonte: Advocacia Geral da União, Consultoria Jurídica junto ao Ministério da Saúde (AGU, 2017).

Em face da relevância da judicialização, o Supremo Tribunal Federal (STF) já reconheceu a repercussão geral do questionamento sobre os limites da intervenção judicial sobre as políticas públicas de saúde. ${ }^{1} \mathrm{O}$ instituto da repercussão geral caracteriza-se quando há o reconhecimento de que determinada questão apresentada ao STF transcende o interesse das partes, por apresentar especial relevância jurídica, política, social ou econômica (artigo 102, $\$ 3^{\circ}$, da CF/88). Reconhecida a repercussáo geral, a decisão subsequente vinculará as instâncias inferiores em casos idênticos.

A análise e crítica majoritárias à judicialização, desenvolvidas até hoje, são dirigidas: (i) ao envolvimento excessivo do Poder Judiciário na esfera políticoadministrativa e (ii) à sua interferência política no planejamento e execução das políticas públicas, levando (iii) à subversão da lógica público-coletiva em nome da tutela de interesses individuais, (iv) usualmente por pessoas em melhores condições de arcar, por si só, com gastos jurídicos e em saúde, gerando maior iniquidade no acesso ao SUS (DALLARI, 2007, 2010; MARQUES, 2008; BRASIL, 2013, 2017; LOPES; ASENSI; SILVA JR., 2017; MOREIRA; RIBEIRO; OUVERNEY, 2017; SANTOS et al., 2018; ROCHA; SILVA; ASENSI, 2018; CAMPOS NETO; GONÇALVES; ANDRADE, 2018). Dallari (2010) entende que o Poder Judiciário, ao avaliar estas demandas, deveria ponderar as reivindicaçóes recebidas, à luz do arcabouço jurídico-normativo disponível. Ao não fazê-lo, estaria gerando um descompasso financeiro, retirando recursos destinados ao atendimento 
da coletividade para atender demandas individuais, corrompendo a própria racionalidade administrativa do Sistema Único de Saúde brasileiro.

Esta perspectiva de crítica destaca a atuação do Poder Judiciário na tutela de demandas que envolvam políticas de saúde, o que é visto como interferência indevida no planejamento do Poder Executivo, transferindo o poder decisório para o Judiciário de resoluções que seriam originalmente políticas e, consequentemente, de competência dos gestores do setor saúde (SILVA; SCHULMAN, 2017; PAIM et al., 2017; NEVES; PACHECO, 2017; LISBOA; SOUZA, 2017; ANDRADE et al., 2018; MARTINI; CHAVES, 2018; DADALTO; AFFONSECA, 2018).

Marques e Dallari (2007) - citadas amiúde por outros autores - defendem que, neste cenário, as decisóes judiciais acabam por definir políticas públicas, à margem das normas jurídicas que as regulam. Elas sustentam que "a 'judicialização da política' e a sobreposição das decisóes judiciais e do arcabouço normativo, às opçóes políticas, representam uma ameaça à própria democracia e à complexidade interna desses sistemas" (idem, p. 106), na medida em que o Poder Judiciário age sem levar em conta as políticas públicas sociais, corre o risco de atuar fora de seus limites estruturais e logísticos. Acompanhadas por outros pesquisadores - como Amaral (2004) e Santos (2009), Lopes, Asensi e Silva Júnior (2017), Paim et al. (2017) e Andrade et al. (2018) -, caracterizam a judicialização como uma interferência indevida do Judiciário que, fugindo à sua estrutura institucional, decide politicamente questôes típicas do Poder Executivo, e "acaba por incorporar o ritmo, a lógica e a prática das decisóes judiciais" à gestão pública (MARQUES; DALLARI, 2007, p. 106).

Segundo este entendimento, as decisões judiciais reverberariam grave e negativamente sobre as políticas de saúde, pois arriscariam substituir as instituiçôes competentes e democraticamente legitimadas, definindo os conteúdos e serviços de saúde, realizando ingerências diretas nas políticas públicas, não se limitando a garantir a sua efetividade. Estas críticas fundam-se no entendimento de que a garantia e a promoção da saúde, em moldes constitucionais, seriam tarefas tipicamente políticas, centradas no Estado e nas suas instâncias público-administrativas do Poder Executivo, ameaçadas por uma ação exacerbada e indevida do Poder Judiciário.

A crítica está inserida nos marcos moderno-industriais, e na visão clássica das instituiçôes e atuação políticas, que compreende o papel do Estado-gestor como propulsor e locus, por excelência, da política e dos direitos humanos. Sob este viés, a judicialização representa uma ameaça ao exercício desta gestão política clássica 
e uma inversão de papéis, que limitaria a autonomia dos gestores e subverteria a racionalidade administrativa, à medida que o Poder Judiciário invadiria atribuiçóes da Administração Pública - sob a ótica da tripartição clássica dos Poderes - e a gestão democrática do Sistema, além de intensificar a iniquidade do acesso à saúde (SILVA; SCHULMAN, 2017; PAIM et al., 2017; NEVES; PACHECO, 2017; SANTOS et al., 2018; ROCHA; SILVA; ASENSI, 2018; CAMPOS NETO; GONÇALVES; ANDRADE, 2018).

Esta compreensão "clássica" da política moderna dialoga também com uma noção muito específica de cidadania, circunscrita a um papel complementar às ações do Estado como palco (e simultaneamente) ator político por excelência. Ao citoyen resta o papel de legitimar as açóes do Estado, sempre nos moldes e espaços da política tradicional. É um tipo de sistema fechado, em que a participação é legitimadora e, ao mesmo tempo, é regulada e legitimada pelo Estado e pelos atores políticos tradicionais. Neste modelo, a democracia participativa apenas acolhe uma forma muito específica de participação, centrada na escolha de representantes e estabelecimento de programas que, uma vez postos em prática, não necessariamente refletem ou são fiéis àquilo que, pela participação popular (de todo fragilizada nos espaços do SUS), foi deliberado.

Esta noção clássica de cidadania, albergada pelo Estado democrático de direito, remete ao conceito de autonomia pública em Habermas (2003), isto é, ao exercício de uma autogestão na esfera pública, participação na esfera das decisóes públicas, mediada pelos espaços institucionais do Estado e pelo sistema jurídico - que é a linguagem própria do Estado e da política. Para Habermas, neste constructo, o Direito seria o medium estabilizador da integração em sociedades complexas, pois reduziria normativamente a tensão das relações intersubjetivas, estabelecendo regras de conduta, parâmetros de "certo e errado" previamente acordados e conhecidos, reduzindo assim a pressão de decisôes pragmáticas e morais por parte dos indivíduos.

No modelo político da modernidade industrial, é o Estado-nação que delimita e escalona o controle e a participação sociais, promovendo as possibilidades e modelos de emancipação social, como início (instrumento legitimador) da cidadania e seu fim: legitimá-lo. Isto é, no contexto da primeira modernidade, as "regras da democracia restringem-se à escolha dos representantes políticos e à participação na elaboração de programas políticos" (BECK, 2010, p. 285). Contudo, devido ao próprio aprofundamento do sistema democrático, ampliação e universalização de direitos 
sociais, os indivíduos são liberados das amarras da política moderno-industrial e da predefinição rígida de lugares e funçôes para o exercício da política. Com o processo de individualização, há uma deslocalização da política e as pessoas são "remetidas a si mesmas para a obtenção dos meios materiais de sua existência” (BECK, 2010, p. 122), utilizando de todos os meios disponíveis para garantir seus legítimos interesses. O que se tem, assim, é uma espécie de privatização da esfera pública habermasiana, ou um privatismo político como denomina Beck (2010), com a ampliação do potencial político da esfera privada através de canais náo tradicionalmente políticos - considerando os atores e formas políticas típicas da sociedade industrial - e uma contraditória responsabilização individual pela garantia de direitos de cidadania.

$\mathrm{Na}$ modernidade reflexiva, assim, o Estado, os atores e os espaços tradicionais da política deslocam-se do centro da arena decisória. O controle que antes era exercido indiretamente, pelo voto, pela participaçáo nos espaços institucionais, pela clássica tripartição de Poderes, e assim por diante, perde espaço para um controle e pressão, potencializados pelo aprofundamento e ampliação dos direitos sociais. Considerando este shift dialético-reflexivo, nosso objetivo é rediscutir a judicialização no contexto das profundas mudanças sociais e transformações no espectro político institucional, buscando contribuir para o entendimento do fenômeno na contemporaneidade.

\section{Judicialização e subpolítica médica}

A ampliação do fenômeno da judicialização na saúde permite que, no quadro da Modernidade reflexiva e do processo de individualização, seja ultrapassada a fronteira da crítica tradicional. Com o estabelecimento dos direitos fundamentais e o aprofundamento da participação e maior consolidação das instâncias jurídicodemocráticas, parece ter emergido uma nova cultura política, no Brasil. Reconhecida a titularidade de direitos e a obrigaçáo do Estado na sua garantia, os cidadãos passam a recorrer a meios não tradicionais de intervenção política, de pressão e de controle público, para defender seus interesses.

Neste processo, o direito à saúde é coletivamente percebido como um direito individual, que deve ser individualmente perseguido por todos. Ainda que o sistema brasileiro se declare universal, a judicialização é um fenômeno marcado pelo acesso à informação, pela educação em direitos (conhecimento de seus direitos) e pelo consumo de serviços especializados (advogados, médicos). É neste sentido que "a 
participação nas proteçôes e benefícios materiais do welfare state pressupôe na grande maioria dos casos participar da força de trabalho" (BECK, 2012, p. 33).

A judicialização, assim, pode ser vista como fenômeno típico do processo de individualização. Não apenas por remeter ao indivíduo a garantia de seu direito à saúde, mas por reduzir esse direito, em grande parte, ao universo do indivíduo trabalhador ou à burguesia assalariada, isto é, ao indivíduo individualizado, inserido no mercado de trabalho e nas cadeias de consumo da esteira de produçáo das biografias individuais. Para Beck (idem), "a participação no trabalho, por sua vez, pressupóe uma participação na educação, e ambos pressupóem a prontidão a ser móbil". Enquanto as políticas sociais pressupóem princípios de coletividade, simultânea e contraditoriamente, são pensadas e direcionadas cada vez mais aos indivíduos. Isto reforça a lógica de responsabilização individual pela identificação, avaliação e decisões quanto aos riscos socialmente produzidos, sob pena de exclusão do mercado de trabalho e dos meios materiais de sobrevivência. Abandonados às suas decisóes, os indivíduos são responsabilizados pela maneira como respondem aos riscos e pelas consequências de suas escolhas. A judicialização, sob muitos aspectos, é uma síntese do processo de individualização:

Essa abordagem das situaçōes, que procura atravessar as fronteiras institucionais, resulta de sua dependência institucional (no mais amplo sentido): os indivíduos desonerados se tornam dependentes do mercado de trabalho e consequentemente da educação, do consumo, das regulaçóes sociojurídicas, do planejamento viário, das ofertas de produtos de consumo, das oportunidades e tendências no aconselhamento e no acompanhamento médico, psicológico e pedagógico (BECK, 2010, p. 194).

Em contrapartida, responde-se a este fenômeno com as velhas formas da sociedade industrial: mais tecnologia, mais abertura ao mercado, mais espaços institucionais de governo. As decisões judiciais e a reação da Administração Pública são marcadas pela compreensão de que o acesso a bens e serviços e a medicalização de suas demandas são a única resposta viável. Remetendo-nos a uma antiga crítica de Illich (1975) à crença equivocada de que o nível de saúde de uma população é diretamente proporcional aos investimentos, despesas e consumo médicos. Isto é um reflexo da atuação subpolítica da medicina sobre a esfera pública e os estilos de vida individualizados, resultantes da ampliação da ação (subpolítica) da medicina. Um saber compreendido como técnico e não político, e que ao mesmo tempo dita, crescentemente, os rumos das políticas públicas de saúde. 
Pode-se caracterizar a judicialização como um fenômeno ao mesmo tempo político e não político. A crítica tradicional é feita: 1) a uma atuação indevida e política do Poder Judiciário sobre questôes próprias da gestão de políticas públicas; 2) à disputa entre interesses individuais e coletivos; e 3) às elites (econômicas e culturais) que teriam condiçôes ótimas ou satisfatórias de acessar os mecanismos particulares para garantia de seus interesses, agravando iniquidades no acesso à saúde em relação aos socialmente mais vulneráveis.

Contudo, passa ao largo dessa reflexão majoritária o próprio fundamento fático das demandas, que é construído pelo saber médico, cuja atuação favorece riscos e situações de ameaça por ele mesmo construído, e que se propóe, no entanto, a reduzir. Uma típica atuação subpolítica, nos termos de Beck (2010, 2012), isto é, uma tomada da política por novos atores e discursos tradicionalmente vistos como não políticos, próprios de uma esfera privada de interesses financeiros, técnicos e científicos, como os saberes e práticas da medicina.

No caso específico da subpolítica médica, e no bojo da judicialização, os efeitos iatrogênico-sociais podem ganhar contornos mais extremos. Este aspecto é muito importante e pouco discutido pela crítica tradicional que vem sendo feita à judicialização: o quanto ela potencializa a ação subpolítica da medicina, que instrumentaliza através do Poder Judiciário interesses econômicos e (sub)políticos, mantendo-se intocada pelo controle e regulação democráticos. Numa sociedade marcada pelo risco, pelo mercado e pela individualização, a influência subpolítica da medicina amplia-se consideravelmente. Produz-se, dessa forma, e nas palavras de Beck (2010, p. 311), "uma fome insaciável pela medicina: um mercado em constante expansão para os serviços da profissão médica, que se ramificam em alcance e profundidade". Em especial, quando pensamos na dependência de saberes especializados e como a responsabilidade individual e a saúde assumem um lugar central, como requisitos para a inserção do indivíduo no mercado de trabalho, em um contexto de (auto)produção biográfica (BECK; BECK-GERNSHEIM, 2002).

Tal atuação subpolítica médica não é questionada, e tampouco há espaço para isto, no curso do processo judicial. Não há controle jurídico, político, social ou de nenhuma outra natureza sobre as decisóes impostas pelo saber dos especialistas médicos (a exceção seria da própria categoria profissional médica, quando convocada a se manifestar). Isto transmuta o direito constitucional à saúde reconhecido formalmente a partir dos movimentos sociais por democracia no país. Emerge um 
"direito marcado pela medicina" (BECK, 2010, p. 311), que gera uma expansão do campo de atuação médica, do mercado e pesquisa para a indústria de tecnologia em saúde, sem garantia de segurança ou efetividade na demanda judicial em saúde.

[...] a política democraticamente legitimada, com seu instrumental de controle, envolvendo direito, dinheiro e informação (esclarecimento dos consumidores, por exemplo), dispóe de instrumentos indiretos de poder, capazes de oferecer a seus "longos intervalos de aplicação" (implementação) possibilidades adicionais de controle, correção e atenuação em contrapartida; a subpolítica do progresso é de um imediatismo que dispensa implementação. Nela, tanto executivo como Legislativo [e Judiciário, acrescento] estão conjugados nas mãos da pesquisa e da práxis médica (ou seja, ligados à indústria, ao gerenciamento empresarial). É o modelo do mandato ilimitado, que ainda não conhece a divisão dos poderes e junto ao qual as metas sociais só precisam ser reveladas aos afetados depois de cumpridas, retrospectivamente como efeitos colaterais. (BECK, 2010, p. 308).

Importante destacar que:

1) enquanto a atuaçáo dos Poderes pode ser minuciosamente fiscalizada, exigindo que respeitem os princípios constitucionais gerais e, especialmente, os princípios constitucionais da administração pública (legalidade, impessoalidade, moralidade, publicidade e eficiência - art. 37);

2) enquanto os fundamentos materiais e processuais das demandas judiciais são exaustivamente expostos, debatidos, rebatidos, contra-arrazoados e julgados;

3) enquanto os limites da competência dos Poderes da República, e da efetividade e abrangência jurídica do direito à saúde, passam por repetidas análises e discussóes hermenêuticas; o saber diagnóstico e a prescrição médica, que dão fundamento e revestem de legitimidade as demandas, são tratados como verdade autoevidente, passando ao largo do debate político da produção da saúde e da vida com uma naturalidade desconcertante.

Nas demandas judiciais sobre políticas de saúde, a própria noção de saúde e doença - táo intensamente debatida no Campo da Saúde Coletiva - e a imperatividade da prestação de serviços ou fornecimento de medicaçóes e insumos tornam-se monopólio médico, passível de julgamento unicamente pelos próprios médicos e, portanto, impermeável ao questionamento e controle externos. E as decisóes dos juízes subordinando-se, consequentemente, ao aval decisório prévio dos médicos. A subpolítica médica, ao se enraizar e ampliar, leva a "padróes decisórios [que] só podem ser 'enfrentados', mesmo em termos políticos ou jurídicos, recorrendo a diagnósticos médicos" (BECK, 2010, p. 310-311). 
Isto é decisivo, pois a atuação subpolítica médica praticamente neutraliza o controle social e jurídico. Tanto a sociedade quanto o Estado acabam se rendendo a normas e conhecimentos medicamente constituídos e monopolizados, numa estratégia reflexiva de mercado. Neste caso, ganhos de direito não correspondem, necessariamente, a ganhos em autonomia e poder democrático. De forma aparentemente contraditória, o aprofundamento do processo de consolidação da democracia e dos direitos fundamentais no Brasil faz emergir uma atuação subpolítica não regulada pelos mecanismos de controle democrático, o que pode contribuir para uma desconstrução dos avanços socialmente construídos, e comprometer a eficácia e segurança das políticas públicas de saúde.

A sociedade civil vê no atendimento intransigente de suas demandas individualizadas a garantia do direito à saúde, o que pode ser muito equivocado. Isto decorre do fato de o Judiciário adotar a compreensão de que o acesso cada vez maior a exames, medicamentos e serviços médicos especializados implica necessariamente em melhorias no nível de saúde individual e da população — o que Illich (1975, p. 31-32) diz decorrer de uma "escolaridade médica muito prolongada" e uma visão "profundamente deformada da realidade", que leva à crença de que "o grau de cuidados no campo da saúde é representado pelas curvas de distribuição dos produtos da instituição médico-farmacêutica" (ILLICH, 1975, p. 37). O Judiciário, então, crê e impóe tal crença às políticas públicas de saúde. Mais que isso, a judicialização da saúde parece completar o mecanismo subpolítico da medicina, esta articulação historicamente construída entre pesquisa, ensino e prática profissional. Uma articulação que ganha contornos peculiares no contexto das ondas de afirmação neoliberal que advogam a privatização das políticas de saúde no Brasil. A medicina conseguiu conciliar e monopolizar institucionalmente a pesquisa, o ensino e a prática, ao tempo que consolida seu poder subpolítico (BECK, 2010).

Agrega-se a esta arquitetura organizacional a possibilidade de atuação através do Poder Judiciário e, assim, a judicialização parece atender a interesses políticos diferentes, mais caracteristicamente tecnocientíficos e econômicos, do que propriamente democráticos. De um lado, obriga o Estado a proceder a verdadeiros testes clínicos de medicamentos, através do SUS e, de outro lado, coopta-o como consumidor de bens e serviços médico-farmacológicos, sem necessariamente passar pelo crivo técnico e democrático da incorporação de tecnologias, no âmbito do SUS. Seja pela força de mandados judiciais, ou pela "prevenção" de açôes judiciais e dos 
custos decorrentes, através da prévia incorporação destas demandas individuais, e apesar da criação de novos espaços institucionais de avaliação e decisão; o Poder Executivo passa a incorporar tecnologias sem os critérios técnicos de segurança, necessidade e eficácia e, portanto, sob risco.

A atuaçâo subpolítica da medicina impacta sobre políticas públicas estabelecidas, avaliações epidemiológicas e na (re)formulação de políticas públicas por fora dos espaços de participação e deliberação do SUS (Conselhos, Comissóes Intergestores), de instâncias decisórias dos Poderes Executivo e Legislativo, e mesmo dos mecanismos de controle jurídico-processuais - uma vez que o saber médico é impermeável a questionamentos e controles externos à medicina. Assim, o alcance político das decisóes médicas é consideravelmente ampliado e fortalecido, na medida em que atinge não apenas a formulação e execução de políticas públicas (policies), como o conteúdo jurídico e extensão política (politics) do direito à saúde.

Nas estratégias da privatização do SUS, o setor privado quer administrar, com financiamento público, os serviços em saúde. A judicialização instrumentaliza, em alguma medida, estas pretensões e pressões subpolíticas. O setor privado reconhece o Estado como grande "consumidor" de seus serviços e a judicialização, legitimada e incentivada por setores da categoria médica, impóe ao Estado o consumo de procedimentos e medicamentos não disponibilizados pelo SUS, ou que não há em número suficiente, ou na "marca" querida e assim por diante, decorrentes de diagnósticos, prescriçôes e aconselhamentos médicos. A judicialização promove, assim, a reserva de mercado para a indústria médico-hospitalar e farmacêutica.

Nesta perspectiva de análise, a judicialização intensifica a influência decisória da medicina nas políticas públicas de saúde, atendendo a demandas de mercado e clínicas (de pesquisa), demandas da indústria médico-hospitalar e farmacêutica, à revelia do controle democrático e mesmo técnico, que buscaria algum nível de segurança e eficácia na promoção do direito à saúde, na "redução do risco de doença e de outros agravos e ao acesso universal e igualitário às açôes e serviços para sua promoção, proteção e recuperação" (art. 196, CF/88).

De forma intencionalmente generalizada, podemos pensar na judicialização como um fenômeno promotor, no cenário brasileiro, do que Beck (2010, p. 311) chama de "estratégias reflexivas de mercado". E a medicina - que já monopoliza o desenvolvimento da pesquisa, do ensino e das práticas médicas e da definição de 
riscos à saúde - imprime sua marca e controle sobre as decisóes jurídicas que, por sua vez, pressionam de forma irresistível as decisões do Poder Executivo.

\section{Considerações finais}

Importante repensar a judicialização, reconhecendo a atuação intensamente política da medicina, abrindo novas perspectivas para o debate e entendimento crítico dessa atuação, suas consequências, fins e riscos reflexivamente construídos. A judicialização da saúde, associada à subpolítica médica, pode ter consequências sérias para o projeto de saúde pública, universal e democrática no Brasil. Ela pode levar a consequências mais amplas, sistêmicas e, ao mesmo tempo, sutis, do que o redirecionamento de parte do Erário, um descompasso no financiamento das políticas de saúde ou a subversão da racionalidade administrativa.

Se um direito marcado pela medicina, e um Poder Judiciário refém de normas e fatos "medicinalmente produzidos", tem o potencial para promover injustiças no âmbito do direito privado, em discussóes sobre erro médico, este potencial se amplia exponencialmente no campo das políticas públicas e da assistência à saúde em níveis populacionais. É essencial problematizar e tentar compreender os mecanismos ocultos e consequências complexas de uma judicialização pautada pela subpolítica médica. E parece-nos inócuo responder a um fenômeno tão intrinsecamente reflexivo, com as mesmas velhas respostas da sociedade industrial: mais ordenação e controle, mais protocolos e espaços institucionais de avaliação e decisão técnicas, mais investimento e tecnologia. Esperamos que este artigo provoque novos questionamentos e inquietaçóes, e estabeleça um ponto de partida possível para novos desdobramentos analíticos, e respostas mais coerentes ao fenômeno da judicialização das políticas de saúde. ${ }^{2}$

\section{Referências}

ANDRADE, R. G. S. et al. Processos judiciais para aquisição de bomba de insulina em Ribeirão Preto. Rev. Bioét., Brasília, v. 26, n. 1, p. 102-108. Jan 2018.

AMARAL, G. Teoria dos direitos fundamentais. In: TORRES, R. L. (Org.). Teoria dos direitos fundamentais. $2^{\mathrm{a}}$ ed. Rio de Janeiro: Renovar, 2004, p. 1- 48.

BECK, U. Ecological Enlightenment: Essays on the politics of the risk society. New York-USA: Humanity Books, 1995. 
. La sociedad del riesgo mundial: En busca de la seguridad perdida. Barcelona: Paidós, 2008. . Sociedade de risco: rumo a uma outra modernidade. São Paulo: Editora 34, 2010. . A reinvenção da política: rumo a uma teoria da modernização reflexiva. In: GIDDENS, A.; LASH, S.; BECK, U. Modernização reflexiva: política, tradição e estética na ordem social moderna. São Paulo: UNESP, 2012, cap. 1, p. 11- 87.

BECK, U.; BECK-GERNSHEIM, E. Individualization: Institutionalized Individualism and its Social and Political Consequences. London: Sage Publications, 2002.

BECK-GERNSHEIM, E. The Social Implications of Bioengineering. New Jersey-USA: Humanities Press, 1995.

AGU - Advocacia Geral da União. Justiça Federal e Apontamentos na seara das Justiças Estaduais. Brasília, DF: AGU, 2013. Disponível em: <https://goo.gl/aK8WTA>. Acesso em: 18 dez. 2013. ADVOCACIA GERAL DA UNIÃO. Judicialização da saúde no Brasil: principais projetos desenvolvidos pela Coordenação de Assuntos Judiciais. Brasília, DF: AGU, 2017. Disponível em: < https://goo.gl/QnPGWF>. Acesso em: 20 out. 2017.

CAMPOS NETO, O. H.; GONÇALVES, L. A. O.; ANDRADE, E. G. A judicialização da Saúde na percepçáo de médicos prescritores. Interface, Botucatu, v. 22, n. 64, p. 165-176, mar. 2018.

DADALTO, L.; AFFONSECA, C. A. Considerações médicas, éticas e jurídicas sobre decisões de fim de vida em pacientes pediátricos. Rev. Bioét., Brasília, v. 26, n. 1, p.12-21, jan. 2018.

DALLARI, S. G. Controle judicial da política de assistência farmacêutica: direito, ciência e técnica. Physis, Rio de Janeiro v. 20, n. 1, p. 57-75, 2010.

DALLARI, S. G. A justiça, o direito e os bancos de dados epidemiológicos. Ciênc. saúde coletiva, Rio de Janeiro, v. 12, n. 3, p. 633-641, jun. 2007.

HABERMAS, J. Direito e Democracia: entre facticidade e validade. 2a ed. Rio de Janeiro: Tempo Brasileiro, 2003.

IANNI, A. M. Z. Questôes contemporâneas sobre natureza e cultura: notas sobre a Saúde Coletiva e a sociologia no Brasil. Saude soc., São Paulo, v. 20, n. 1, p. 32-40, Mar. 2011.

ILLICH, I. A Expropriação da Saúde: Nêmesis da Medicina. 3a ed. Rio de Janeiro: Editora Nova Fronteira, 1975.

LIPOVETSKY, G. A sociedade da decepção. Barueri, SP: Manole, 2007.

LISBOA, E. S.; SOUZA, L. Por que as pessoas recorrem ao Judiciário para obter o acesso aos medicamentos? O caso das insulinas análogas na Bahia. Ciênc. saúde coletiva, Rio de Janeiro, v. 22, n. 6, p. 1857-1864, jun 2017. 
LOPES, L. M. N.; ASENSI, F. D.; SILVA JUNIOR, A. G. A judicialização indireta da saúde: um estudo de caso sobre a experiência de Cachoeiro de Itapemirim/ES. Rev. Direito Práx., Rio de Janeiro, v. 8, n. 1, p. 285-320, mar. 2017.

MARQUES, S. B. Judicialização do direito à saúde. Rev. Direito Sanit., São Paul, v. 9, n. 2, p. 65-72, out. 2008.

MARQUES, S. B.; DALLARI, S. G. Garantia do direito social à assistência farmacêutica no Estado de São Paulo. Rev. Saúde Pública, São Paulo, v. 41, n. 1, p. 101-107, fev. 2007.

MARTINI, S. R.; CHAVES, A. S. Necessidade de confiança na jurisdição constitucional para efetivação do direito à saúde. Interações, Campo Grande, v. 19, n. 1, p. 77-91, jan. 2018.

MOREIRA, M. R.; RIBEIRO, J. M.; OUVERNEY, A. M. Obstáculos políticos à regionalização do SUS: percepçóes dos secretários municipais de Saúde com assento nas Comissões Intergestores Bipartites. Ciênc. saúde coletiva, Rio de Janeiro, v. 22, n. 4, p. 1097-1108, abr. 2017.

NEVES, P.; PACHECO, M. A. Saúde pública e Poder Judiciário: percepçôes de magistrados no estado do Maranhão. Rev. direito GV, São Paulo, v. 13, n. 3, p. 749-768, dez. 2017.

PAIM, L. F. N. A. et al. Qual é o custo da prescrição pelo nome de marca na judicialização do acesso aos medicamentos?. Cad. saúde colet., Rio de Janeiro, v. 25, n. 2, p. 201-209, abr. 2017.

ROCHA, C.; SILVA, M.; ASENSI, F. Juridicização engajada da adolescência: sobre um caso de internação psiquiátrica compulsória. Saude soc., São Paulo, v. 27, n. 1, p. 201-214, jan. 2018. SANTOS, L. SUS: contornos jurídicos da integralidade da atenção à saúde In: KEINERT, T. M. M.; PAULA, S. H. B.; BONFIM, J. R. A. (Orgs.). As açóes judiciais no SUS e a promoção do direito à saúde. São Paulo: Instituto de Saúde, 2009, 2009, p. 63-72.

SANTOS, E. C. B. et al. Judicialização da saúde: acesso ao tratamento de usuários com diabetes mellitus. Texto contexto - enferm. Santa Catarina, v.27, n.1, p. 1-7, 2018.

SARLET, I. W.; FIGUEIREDO, M. F. Algumas consideraçóes sobre o direito fundamental à proteção e promoção do direito à saúde aos 20 anos da Constituição Federal de 1988. In: KEINERT, T. M. M.; PAULA, S. H. B.; BONFIM, J. R. A. (Orgs.). As açóes judiciais no SUS e a promoção do direito à saúde. São Paulo: Instituto de Saúde, 2009, p. 25-63.

SILVA, A. B.; SCHULMAN, G. (Des)judicialização da saúde: mediação e diálogos interinstitucionais. Rev. Bioét., Brasília, v. 25, n.2, p. 290-300, ago 2017.

SOLON, A. M. Ética, Cidadania e direito à saúde. In: KEINERT, T. M. M.; PAULA, S. H. B.; BONFIM, J. R. A. (Orgs.). As açóes judiciais no SUS e a promoção do direito à saúde. São Paulo: Instituto de Saúde, 2009, p. 21-24. 


\section{Notas}

${ }^{1}$ Conforme notícia do STF, datada de 28/09/2016, tiveram repercussão geral reconhecida os Recursos Extraordinários (REs) n. 566471 e n.o 657718, que tratavam do fornecimento de remédios de alto custo não disponíveis na lista do Sistema Único de Saúde (SUS) e de medicamentos não registrados na Agência Nacional de Vigilância Sanitária (Anvisa). Disponível em: https://goo.gl/E93nQw. Acesso em: dez. 2017.

${ }^{2}$ T.M. Leão e redigiu o artigo e aprovou a versão final. A. M. Z. Ianni revisou o artigo e aprovou a versão final. 


\section{Abstract}

\section{Judicialization and Medical Sub-Politics}

The phenomenon of judicialization and the growing litigation in health demands have gained increasing importance - not only academic but also practical. In Brazil, this is usually seen by the academic criticism as the involvement of the Judiciary in the political sphere and its activity, as an interference in the planning of public policies. The judicial decisions would end up by defining policies, thus diverging from the democratic model of industrial modernity based upon the separation of Powers. Various research projects have argued that the Judiciary tends to attend to these demands, which invoke as their legal foundation the right to health, as defined by the constitutional norms, and based upon medical reports. This article discusses judicialization and medical sub-politics in the contemporary scene. In the light of contemporary social changes, judicialization can also be characterized as an echo of a reflexive process of modernity, in which established fundamental rights point to a new political culture. Citizens use non-traditional means of intervention and public and judicial control to defend their interests and rights. The very factual foundation of the demands is constructed reflectively by medical knowledge, impermeable to the traditional forms of external control. This generates a judicialization controlled by medicine and favors the expansion of the field of, activity, market and research for the medical, hospital and pharmaceutical industries. Thus, judicialization can attend to the more characteristically techno-scientific and economic interests than to democratic ones. Both society and the State end up by being obliged to have recourse to norms and knowledge medically constituted and monopolized, in a reflective market strategy. It is important to rethink judicialization in the light of the intensely political activity of medicine, thus opening up new prospects for the debate and critical understanding of this activity, its consequences, purposes and reflectively constructed risks.

> Keywords: judicialization; medicalization; individualization; medical sub-politic; risk society; public health. 